\title{
Patient preference regarding assessment of clinical follow-up after percutaneous coronary intervention: the PAPAYA study
}

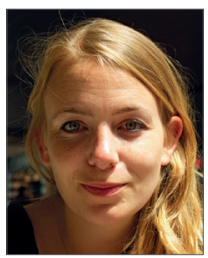

Marlies M. Kok ${ }^{1}$, MD; Clemens von Birgelen ${ }^{1,2 *}$, MD, PhD; Ming Kai Lam¹, MD, PhD;

Marije M. Löwik ${ }^{1}$, PhD; K. Gert M. van Houwelingen ${ }^{1}$, MD; Martin G. Stoel ${ }^{1}$, MD, PhD; J. (Hans) W. Louwerenburg', MD; Frits H.A.F. de Man¹, MD, PhD; Marc Hartmann' ${ }^{1}$ MD, PhD; Carine J.M. Doggen², PhD; Janine A. van Til², PhD; Maarten J. IJzerman², $\mathrm{PhD}$

1. Department of Cardiology, Thoraxcentrum Twente, Medisch Spectrum Twente, Enschede, The Netherlands; 2. Department of Health Technology and Services Research, MIRA, Institute for Biomedical Technology and Technical Medicine, University of Twente, Enschede, The Netherlands

This paper also includes supplementary data published online at: http://www.pcronline.com/eurointervention/97th_issue/288

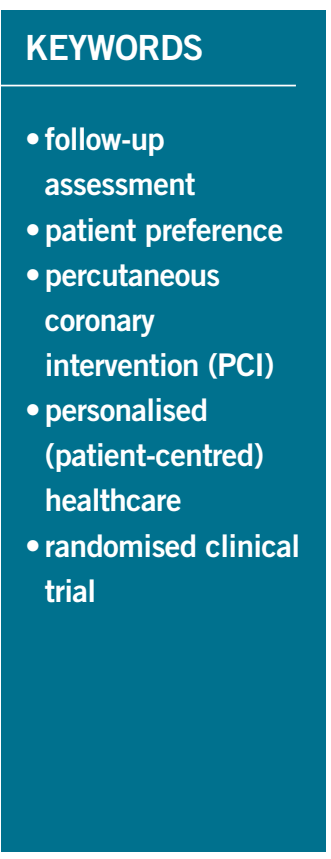

\section{Abstract}

Aims: To keep patients in long-term clinical follow-up programmes after percutaneous coronary intervention (PCI), knowledge of the patient-preferred mode for follow-up assessment is crucial. We systematically assessed patient preference, and explored potential relationships with age and gender.

Methods and results: In the prospective, observational PAPAYA study (ClinicalTrials.gov: NCT02189070), 2,566 patients, treated by PCI between June 2008 and May 2012, were invited to participate in a postal survey on the patient-preferred mode (postal questionnaire, telephone or e-mail consultation) and frequency of follow-up assessment. A total of 1,797 (70.0\%) patients responded. The vast majority preferred completing postal questionnaires $(1,248[69.9 \%])$ as compared to telephone $(240[13.4 \%])$ or e-mail-based approaches $(227[12.7 \%])(\mathrm{p}<0.001)$. With increasing age, there was a gradual decline in preference for e-mail ( $\mathrm{p}<0.001$ ); the youngest patients ( $\leq 60$ years) preferred e-mail-based follow-up more often than the oldest $(21.1 \%$ vs. $3.1 \%)$. Nevertheless, $79.9 \%$ of the youngest preferred to be approached in ways other than by e-mail. Women more often preferred approaches other than e-mail $(94.1 \%$ vs. $87.3 \%$, p $<0.001)$.

Conclusions: Patients showed a distinct preference for completing postal questionnaires rather than being approached by telephone or e-mail. Younger patients accepted e-mail-based follow-up more often, but the majority of the youngest patients still preferred approaches other than by e-mail.

*Corresponding author: Department of Cardiology, Thoraxcentrum Twente, Medisch Spectrum Twente, Haaksbergerstraat 55, 7513 ER Enschede, The Netherlands.E-mail: c.vonbirgelen@mst.nl 


\section{Abbreviations}

CABG coronary artery bypass grafting

CAD coronary artery disease

DES drug-eluting stents

MI myocardial infarction

PCI percutaneous coronary intervention

\section{Introduction}

The collection of long-term clinical follow-up data after percutaneous coronary intervention (PCI) is a key issue of randomised studies and of growing interest for routine clinical practice. Such data have been shown to be highly relevant, as they can reveal an increased risk of very late adverse events ${ }^{1,2}$. For the validity of follow-up, it is important that information is obtained from the maximum achievable number of patients. Successful retention of patients in programmes that collect follow-up data is crucial but remains a challenge, as follow-up rates generally decline over time $^{3}$. In large, well-organised, drug-eluting stent (DES) trials, a decline in mortality-corrected follow-up rates has been reported (98-100\% after one year; $89-96 \%$ after five years) ${ }^{4-6}$. In clinical practice, adherence to long-term follow-up programmes may even be much lower.

When patients are not required to be physically present for follow-up assessment, information may be gathered from national databases, telephone contacts, and web-based or postal surveys. Taking the patients' preference regarding the mode and frequency of follow-up into account is likely to enhance adherence to followup. In addition, it is in keeping with the general trend towards personalised healthcare?

Easy access to internet and e-mail services (internet use and access in The Netherlands is among the highest worldwide, even among the elderly) $)^{8,9}$ might facilitate the collection of followup information. So far, the patient-preferred mode of follow-up after PCI has not been systematically evaluated. Therefore, in the prospective PAPAYA study (PAtient Preference Analysis of Yearly follow-up After PCI; ClinicalTrials.gov: NCT02189070), we assessed the preferred mode and frequency of follow-up data acquisition after PCI.

\section{Methods \\ PATIENT POPULATION}

Between May 2013 and May 2014, we performed the PAPAYA study (PAtient Preference Analysis of Yearly follow-up After PCI) in a consecutive series of patients who, between June 2008 and May 2012, had undergone PCI procedures at Thoraxcentrum Twente in the setting of two large, randomised clinical trials, TWENTE and DUTCH PEERS ${ }^{9,10}$. These trials were performed to compare the safety and efficacy of newer-generation DES in study populations with very limited exclusion criteria.

The present study assessed a broad and heterogeneous patient population that reflects routine clinical practice at our tertiary PCI centre. The characteristics of the participants of the TWENTE and DUTCH PEERS trials have been reported in detail ${ }^{10,11}$. In brief,
TWENTE examined 1,391 "real-world" patients, of whom the majority were treated for acute coronary syndromes, had complex coronary lesions, and met criteria of high procedural risk. DUTCH PEERS (TWENTE II) assessed a total of 1,811 all-comer patients, of whom the majority were treated at Thoraxcentrum Twente. In DUTCH PEERS, the proportions of patients with complex coronary lesions and acute coronary syndrome, in particular ST-elevation myocardial infarction, were very high, and the vast majority of patients had a high procedural risk. The PAPAYA study complied with the Declaration of Helsinki for investigation in human beings and was approved by the institutional review board. All patients had provided written informed consent for participation in the trials.

\section{STUDY DESIGN}

In the prospective, observational PAPAYA study, patients received between May 2013 and May 2014 a single, individually addressed letter that contained an invitation to participate in a survey by completing an enclosed questionnaire, a brief study description, and a prepaid envelope for returning the questionnaire to the study centre at Thoraxcentrum Twente. Patients were assured they would be contacted only once and would not receive any reminders.

The survey collected information about the patient-preferred mode of follow-up assessment (postal questionnaire, telephone, or e-mail-based). In addition, patients were asked to indicate the one or two least preferred approaches of follow-up assessment, the preferred number of follow-up events per year, and the maximum acceptable number of questions per assessment. A translated questionnaire is provided in the supplementary web-based material (Online Table 1). Demographics and clinical characteristics of all invited patients were collected from electronic medical files. The available data allowed comparison of responders and non-responders for explorative assessment of potential bias. To examine the potential impact of age on preferences, responders were divided into four age groups as defined by the (rounded off) boundaries of age quartiles, based on all invited patients.

\section{STATISTICAL ANALYSIS}

Data were reported as frequencies and percentages for dichotomous and categorical variables. Continuous variables were expressed as mean \pm standard deviation (SD). Differences between dichotomous and categorical variables were assessed using the chi-square and Fisher's exact tests, as appropriate; for ordinal data the linear-by-linear association chi-square test was used. Continuous variables were assessed with the Student's t-test. The relationship between age and preference was assessed with nominal regression analyses. Parameters were considered as potential confounders if associations were found with a $p$-value $\leq 0.15$ in univariate analyses. A multivariate nominal regression analysis was then used to adjust for potential confounders. All statistical tests were two-tailed. P-values $<0.05$ were considered statistically significant. Data analysis was performed with SPSS, version 17 (SPSS Inc., Chicago, IL, USA). 


\section{Results}

\section{RESPONDERS AND NON-RESPONDERS}

Of the 2,566 invited patients, 1,797 responded and participated in the survey (70.0\%). Table 1 displays demographics and clinical characteristics of the patients. Responders to the survey were on average older $(67.5 \pm 9.7$ vs. $65.2 \pm 12.3$ years; $p<0.001)$. However, women, who represented $27.0 \%$ of the invited population and were significantly older than men, responded less frequently (456/694 [65.7\%] vs. 1,341/1,872 [71.6\%], p=0.004). Diabetics, current smokers, and patients with a history of myocardial infarction

Table 1. Characteristics of the study population.

\begin{tabular}{|c|c|c|c|c|}
\hline & $\begin{array}{c}\text { All invited } \\
\text { patients } \\
n=2,566\end{array}$ & $\begin{array}{c}\text { Responders } \\
n=1,797 \\
(70.0 \%)\end{array}$ & $\begin{array}{c}\text { Non- } \\
\text { responders } \\
n=769 \\
(30.0 \%)\end{array}$ & $p$-value \\
\hline Age, yrs & $66.8 \pm 10.6$ & $67.5 \pm 9.7$ & $65.2 \pm 12.3$ & $<0.001$ \\
\hline Men & $1,872(73.0)$ & $1,341(74.6)$ & $531(69.1)$ & 0.004 \\
\hline Body mass index, $\mathrm{kg} / \mathrm{m}^{2}$ & $27.9 \pm 4.3$ & $27.7 \pm 4.2$ & $28.3 \pm 4.5$ & 0.005 \\
\hline Chronic renal failure* & $72(2.8)$ & $46(2.6)$ & $26(3.4)$ & 0.24 \\
\hline Hypertension" & $1,381(55.3)$ & $992(56.7)$ & $389(52.0)$ & 0.03 \\
\hline Hypercholesterolaemia & $1,334(53.5)$ & $948(54.4)$ & $386(51.4)$ & 0.17 \\
\hline Current smoker & 622 (24.2) & $385(21.4)$ & $237(30.8)$ & $<0.001$ \\
\hline Diabetes mellitus (any) & $474(18.5)$ & $296(16.5)$ & $178(23.1)$ & $<0.001$ \\
\hline Prior $\mathrm{Ml}^{\ddagger}$ & $696(27.1)$ & $460(25.6)$ & $236(30.7)$ & 0.008 \\
\hline Prior $\mathrm{PCl}$ & 485 (18.9) & $303(16.9)$ & $182(23.7)$ & $<0.001$ \\
\hline Prior CABG & $252(9.8)$ & $179(10.0)$ & $73(9.5)$ & 0.72 \\
\hline Family history of CAD & $1,352(52.7)$ & $940(52.3)$ & $412(53.6)$ & 0.56 \\
\hline \multicolumn{3}{|c|}{ Clinical syndrome at presentation } & & 0.42 \\
\hline STEMI & $283(11.0)$ & $191(10.6)$ & $92(12.0)$ & \\
\hline NSTEMI & $667(26.0)$ & $470(26.2)$ & $197(25.6)$ & \\
\hline Unstable angina & $424(16.5)$ & $287(16.0)$ & $137(17.8)$ & \\
\hline Stable angina & $1,192(46.5)$ & 849 (47.2) & $343(44.6)$ & \\
\hline \multicolumn{3}{|c|}{ Number of lesions treated per patient } & & 0.39 \\
\hline One & $1,739(67.8)$ & $1,224(68.1)$ & $515(67.0)$ & \\
\hline Two & $641(25.0)$ & $451(25.1)$ & $190(24.7)$ & \\
\hline Three or more & $186(7.2)$ & $122(6.8)$ & $64(8.3)$ & \\
\hline At least 1 complex lesion & $1,990(77.6)$ & $1,391(77.4)$ & $599(77.9)$ & 0.79 \\
\hline \multicolumn{5}{|l|}{ Target vessel location } \\
\hline Left main stem & $78(3.0)$ & $53(2.9)$ & $25(3.3)$ & 0.68 \\
\hline $\begin{array}{l}\text { Left anterior } \\
\text { descending artery }\end{array}$ & $1,285(50.1)$ & $906(50.4)$ & 379 (49.3) & 0.60 \\
\hline Left circumflex artery & $772(30.1)$ & $546(30.4)$ & $226(29.4)$ & 0.62 \\
\hline Right coronary artery & 954 (37.2) & $659(36.7)$ & 295 (38.4) & 0.42 \\
\hline Bypass graft & $75(2.9)$ & 58 (3.2) & $17(2.2)$ & 0.16 \\
\hline SYNTAX score & $14.0 \pm 10.8$ & $13.92 \pm 10.7$ & $14.19 \pm 10.9$ & 0.56 \\
\hline \multicolumn{5}{|c|}{$\begin{array}{l}\text { Values are n (\%) or mean } \pm \text { SD. }{ }^{*} \text { Chronic renal failure defined by serum creatinine level } \\
\leq 130 \mu \text { mol/I. "Left ventricular ejection fraction assessed with ultrasound, magnetic } \\
\text { resonance imaging, or left ventricular angiography. } \text { Prior MI, prior PCl, and prior CABG } \\
\text { indicate Ml or revascularisation procedures that occurred before patients were enrolled in } \\
\text { one of the randomised trials and thus before they underwent the index PCI procedures of } \\
\text { the respective randomised trials. CABG: coronary artery bypass grafting; CAD: coronary } \\
\text { artery disease; MI: myocardial infarction; PCl: percutaneous coronary intervention }\end{array}$} \\
\hline
\end{tabular}

(MI) or previous PCI also responded slightly but significantly less often. Between responders and non-responders, there was no significant difference in lesion characteristics, target vessel location, or angiographic SYNTAX score.

\section{PREFERRED APPROACH OF FOLLOW-UP AND RELATIONSHIP WITH AGE AND GENDER}

The vast majority of all responders preferred completing a postal questionnaire $(1,248$ [69.9\%]) rather than being approached via telephone (240 [13.4\%]) or e-mail (227 [12.7\%]) $(\mathrm{p}<0.001$, Table 2). There was a significant, positive relationship between the preference for a postal questionnaire and age (Table 3, Figure 1). Patients aged 60 years or younger preferred least often the postal questionnaire, but this approach was still the favourite option of $63.5 \%$ of these patients and did not differ between patients $\leq 54$ years of age versus patients $55-60$ years of age $(63.8 \%$ vs. $63.4 \%, p=0.42$; threshold of 54 years based on median age of the youngest patient quartile).

Table 2. Preference regarding follow-up assessment stratified by gender.

\begin{tabular}{|c|c|c|c|c|}
\hline & \multirow{2}{*}{$\begin{array}{c}\text { All } \\
\text { responders } \\
(n=1,796)\end{array}$} & \multicolumn{2}{|c|}{ Gender } & \multirow[b]{2}{*}{$p$-value } \\
\hline & & $\operatorname{Men}(n=1,341)$ & Women $(n=455)$ & \\
\hline Age, yrs & $67.5 \pm 9.7$ & $66.6 \pm 9.6$ & $70.1 \pm 9.4$ & $<0.001$ \\
\hline \multicolumn{3}{|l|}{ Preferred approach } & & $<0.001$ \\
\hline Questionnaire & $1,248(69.9)$ & $916(68.8)$ & $332(73.0)$ & \\
\hline Telephone & 240 (13.4) & $165(12.4)$ & $75(16.5)$ & \\
\hline E-mail & $227(12.7)$ & $200(15.0)$ & $27(5.9)$ & \\
\hline No preference & $71(4.0)$ & $50(3.9)$ & $21(4.6)$ & \\
\hline \multicolumn{3}{|c|}{ Least preferred approach* } & & $<0.001$ \\
\hline Questionnaire & $205(8.4)$ & $151(8.6)$ & $54(8.0)$ & \\
\hline Telephone & $1,153(47.3)$ & $883(50.1)$ & $270(40.0)$ & \\
\hline E-mail & $1,079(44.3)$ & $728(41.3)$ & $351(52.0)$ & \\
\hline \multicolumn{3}{|c|}{ Preferred number of questions per contact } & & $<0.001$ \\
\hline 0 & $1(0.1)$ & $1(0.1)$ & $0(0)$ & \\
\hline$<5$ & $237(13.6)$ & 155 (11.8) & $82(19.0)$ & \\
\hline $6-10$ & $964(55.3)$ & $711(54.2)$ & $253(58.7)$ & \\
\hline $11-15$ & 305 (17.5) & $254(19.4)$ & $51(11.8)$ & \\
\hline$>15$ & 235 (13.5) & $190(14.5)$ & $45(10.4)$ & \\
\hline \multicolumn{3}{|c|}{ Preferred number of annual follow-up events } & & 0.06 \\
\hline $0 x^{\pi}$ & $129(7.4)$ & $89(6.9)$ & $40(9.1)$ & \\
\hline $1 x$ & $1,024(59.0)$ & $748(57.7)$ & $276(62.7)$ & \\
\hline $2 x$ & $464(26.7)$ & $365(28.1)$ & $99(22.5)$ & \\
\hline $3 x$ & $34(2.0)$ & $26(2.0)$ & $8(1.8)$ & \\
\hline $4 x$ & $86(5.0)$ & $69(5.3)$ & $17(3.9)$ & \\
\hline
\end{tabular}

Values are $n(\%)$. A few patients did not provide answers to all the survey questions. Preferred approach: missing <20; preferred number of questions and preferred number of annual FUP events missing 21-60. *Indication of up to two least preferred approaches was permitted. "Patients preferred follow-up data collection from healthcare providers and local residents or national registration offices, but not to be contacted themselves. 
A

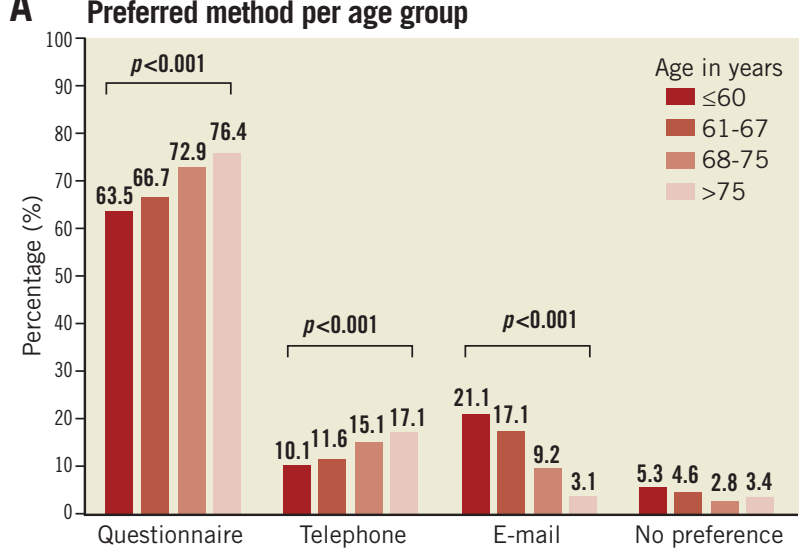

B Least preferred approach per age group

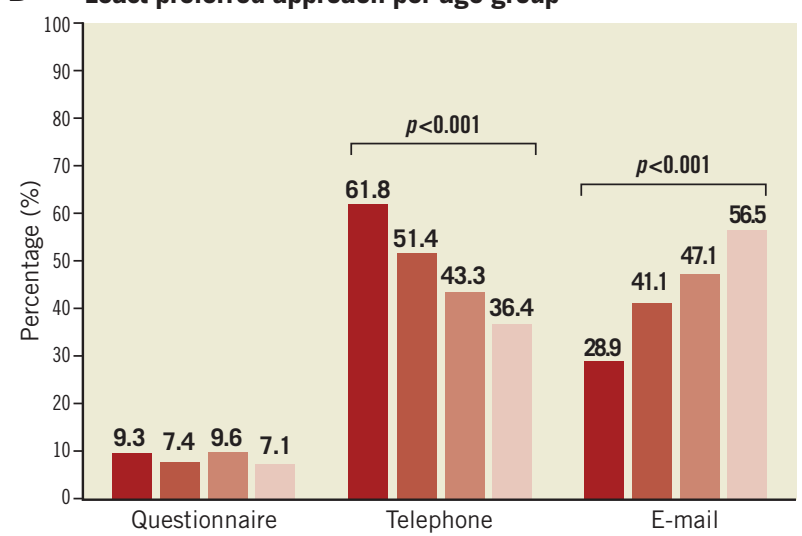

C Preferred number of annual follow-up moments

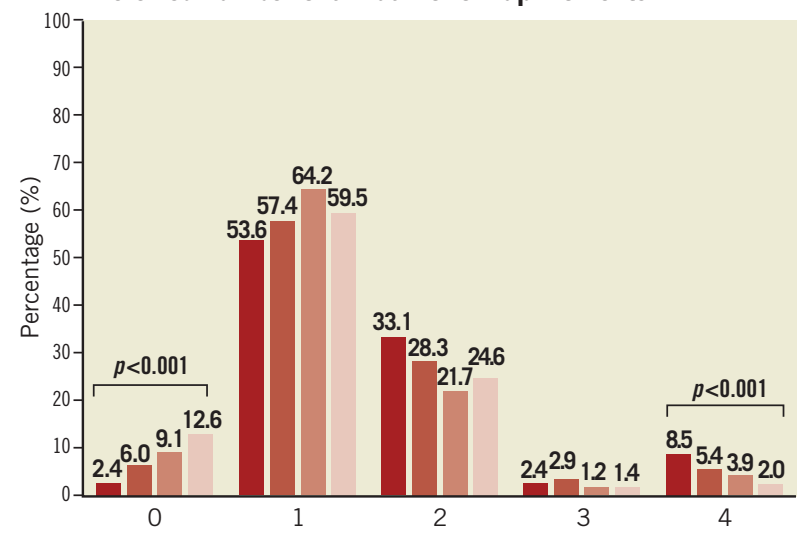

Figure 1. Preferences per age group. A) Preferred method per age group. B) Least preferred approach per age group. C) Preferred number of annual follow-up moments. p-values for ordinal data were calculated with linear-by-linear association of $\chi^{2}$ test.

In addition, there was a significant, gradual decrease in the preference for e-mail-based follow-up with increasing age. In age-based quartiles, the youngest patients $(\leq 60 \mathrm{yrs})$ preferred the e-mail-based follow-up much more often than the oldest ( $>75 \mathrm{yrs}$ ) ( $21.1 \%$ vs. $3.1 \%$ ); nevertheless, $78.9 \%$ of the youngest patients (31-60 years) still preferred to be approached in ways other than by e-mail.

Multivariate analysis showed that age is an independent predictor for preference. Patients in the youngest category ( $\leq 60$ years) had a 7.1-fold increased chance of preferring e-mail-based follow-up as compared to the eldest patients $(>75$ years $)(p<0.001)$. Compared to this same group of elderly patients, patients aged 61-67 years had a 5.7-fold increased chance of preferring e-mail, and patients aged 67-75 years had a 2.9-fold increased chance of preferring e-mail-based follow-up $(\mathrm{p}<0.001)$. Per five years that patients were younger, the chance of preferring e-mail-based follow-up increased by 1.3 times.

Women were significantly older than men $(70.1 \pm 9.4$ and $66.6 \pm 9.6$, respectively, $\mathrm{p}<0.001)$ and less likely to prefer e-mailbased follow-up $(5.9 \%$ vs $15.0 \%, \mathrm{p}<0.001)$. While $18.5 \%$ of women aged 60 years or younger stated that they preferred e-mailbased follow-up, this approach was only preferred by $0.7 \%$ of women older than 75 . In addition, $58.5 \%$ of these elderly women indicated that follow-up via e-mail was their least preferred approach (Online Table 2, Figure 2).

With increasing age, there was a growing acceptance of telephone-based follow-up $(\mathrm{p}<0.001)$, which overall, and in particular among younger patients, was the least preferred approach. Of the 240 patients who preferred to be contacted by telephone, 227 (94.6\%) reported which time of day (morning, afternoon, or evening) they favoured. The majority (53.3\%) preferred to be contacted in the morning, while $23.3 \%$ favoured the afternoon and $23.3 \%$ the evening. Younger patients preferred follow-up telephone calls to be performed in the evening $(43.2 \%$ and $31.4 \%$ for patients $\leq 60$ years and 61-67 years, respectively), while older patients (6875 years and $>75$ years) preferred less often to be called in the evening $(10.3 \%$ and $21.3 \%$, respectively, $\mathrm{p}=0.002)$.

\section{PREFERRED NUMBER OF YEARLY FOLLOW-UP ASSESSMENTS AND NUMBER OF QUESTIONS}

The majority of patients $(59.0 \%)$ preferred a single, yearly follow-up moment and $26.7 \%$ preferred two (Table 2, Figure 1). Patients preferred much less often three or four follow-up moments $(7.0 \%)$ or no personal follow-up moment at all (but data collection from healthcare providers was acceptable) (7.4\%); the latter was most often preferred by the elderly. Most patients $(55.3 \%)$ preferred a maximum number of six to 10 questions per assessment.

\section{Discussion}

The PAPAYA study shows a distinct preference of PCI patients for completing a follow-up postal questionnaire rather than being approached by telephone or e-mail (70\% versus $13 \%$ and $13 \%$, respectively). Multivariate nominal regression analysis showed that age is an independent predictor for preference. The youngest patient group ( $\leq 60 \mathrm{yrs})$ preferred e-mail-based follow-up more often than the oldest ( $21 \%$ versus $3 \%$ ), but still almost four out of five younger patients preferred follow-up approaches other than by e-mail. The gender analysis revealed that in women the acceptance of e-mail-based follow-up was lower than in men. However, it should be noted that women were on average older than men $(p<0.001)$, which may have contributed to their lower acceptance 
Table 3. Preference regarding follow-up assessment in all responders and in age-based groups.

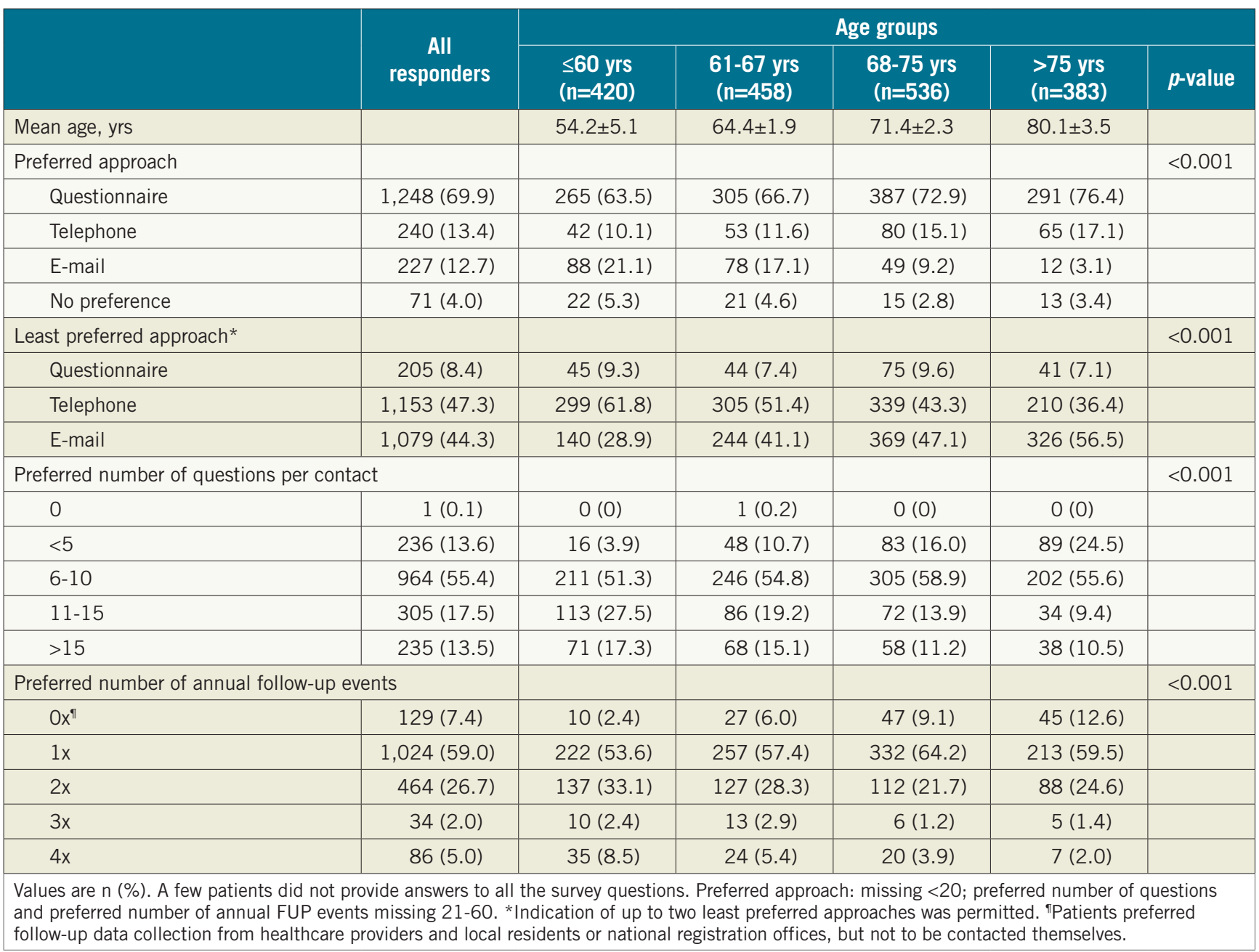

rate of the e-mail-based approach. In the light of the fact that The Netherlands is among the top five countries worldwide with the highest rates of internet use ${ }^{8}$ and access - even among the population aged 65 years and older $^{9}$ - the relatively low acceptance rate of e-mail-based follow-up in the PAPAYA study is remarkable and was certainly not anticipated.

\section{PREVIOUS STUDIES}

To the best of our knowledge, PAPAYA is the first study to assess patient preference regarding follow-up after PCI. The response by $70 \%$ of the invited patients was high. Characteristics of responders and non-responders were similar but showed some differences. Among responders, there was a slight underrepresentation of diabetics and patients with a history of MI or PCI. We speculate that this might partly be related to recurrent visits of healthcare providers that could have resulted in a certain "healthcare overload". Reducing the length of postal and electronic questionnaires has previously been shown to increase the response rate significantly ${ }^{12}$, which is consistent with our finding that assessments should not exceed six to 10 questions. Although intuitively this may seem to be a rather small number of questions for a sufficient assessment of follow-up information, this number is consistent with or even higher than the approximated number of questions that clinicians are able to ask during office visits, considering the high time pressure in current clinical practice.

The Dutch Central Bureau for Statistics has assessed the overall availability and use of the internet in the total population: $95 \%$ of all households have access to the internet ${ }^{9}$, irrespective of educational level or level of income. Furthermore, The Netherlands has the fourth largest number of internet users (74\%) in Europe within the population aged $65-75$ years.

\section{FOLLOW-UP WITHOUT ANY DIRECT PATIENT CONTACT}

Elderly patients are a rapidly growing subpopulation of patients that has more comorbidities and an increased procedural mortality $^{13}$. It is of the utmost importance to assess these patients in clinical trials and follow-up programmes. PAPAYA has shown that one out of eight elderly patients $>75$ years of age, rather than being directly contacted, preferred follow-up data to be collected from healthcare providers, pharmacies, and local residents' or national registration offices. In Denmark, such an approach is embraced by the SORT OUT series of randomised clinical trials that compared 


\section{A Preference for questionnaire}

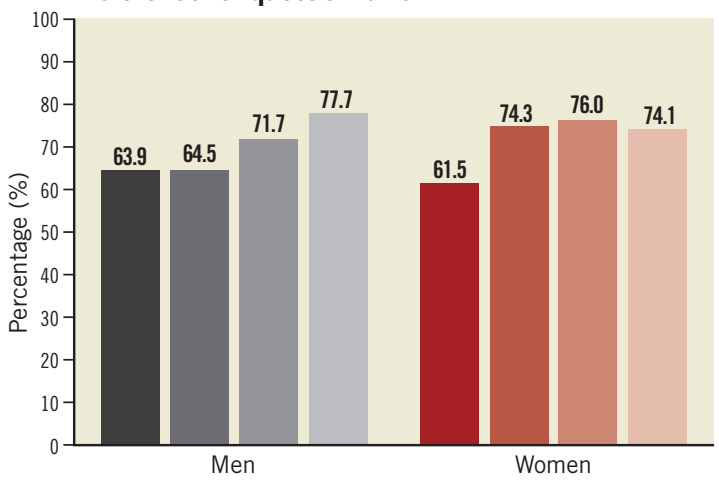

C Preference for e-mail

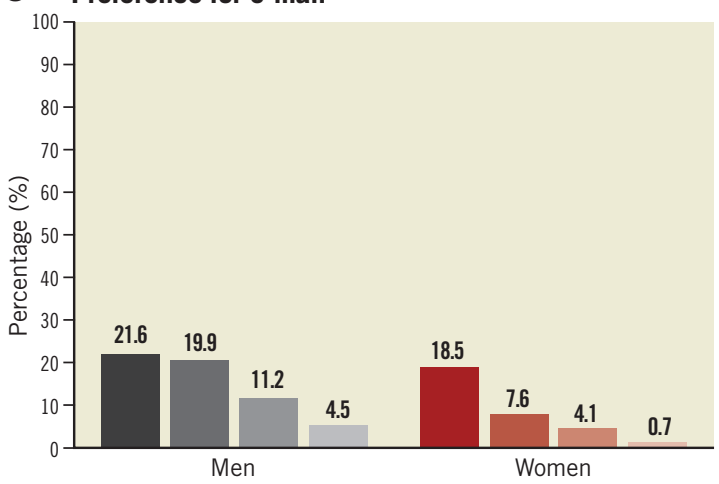

B Preference for telephone

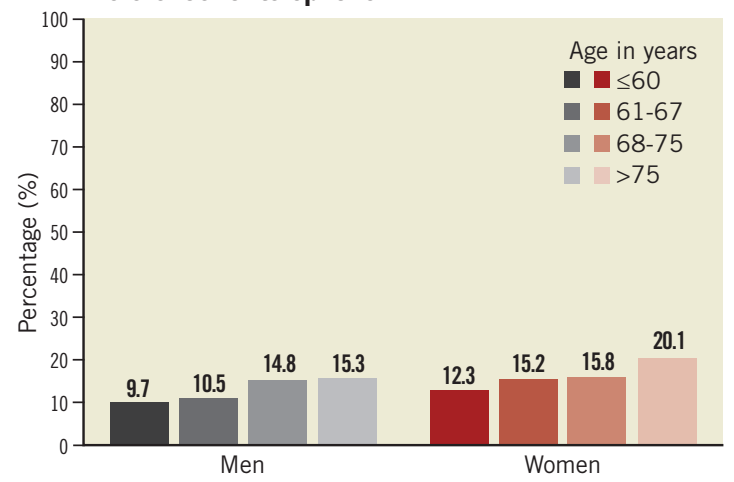

D No preference

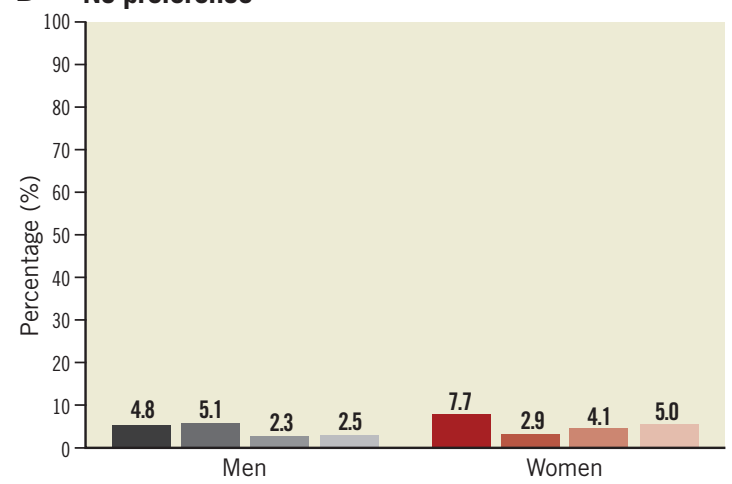

Figure 2. Preferences regarding follow-up assessment of men versus women in age-based groups. A) Preference for questionnaire. B) Preference for telephone. C) Preference for e-mail. D) No preference.

DES in a head-to-head fashion ${ }^{14-16}$. Assessment of the follow-up of these trials is based on national administrative population and healthcare registries of clinical events and procedures, which are used as a standard by the entire Danish health system ${ }^{17}$. This registry-based event detection provides a way to perform randomised studies that fully resemble routine clinical care. This approach has proven to be pragmatic, cost-effective, and may help to facilitate long-term follow-up. Nevertheless, patient-triggered event rates may be typically lower than the event rates of trials with active clinical follow-up. This has previously been suggested to be partly attributable to a potential detection bias (e.g., inaccuracy of discharge coding) $)^{18}$. On the other hand, certain symptom-driven endpoints, such as repeat revascularisation, may be lower if patients are not directly approached by a research team due to the prevention of recall bias. In addition, it is most likely that patients who experience significant symptoms will report this to their general practitioner or the referring cardiologist. The findings of PAPAYA suggest that a registry-based approach, such as applied in the SORT OUT series of trials, will facilitate follow-up assessment in populations with predominantly elderly patients.

\section{IMPLICATIONS}

In current evidence-based healthcare, there is an increasing demand for detailed information on medical procedures and related clinical outcomes that can be obtained either from prospective clinical trials or from registries of routine clinical practice ${ }^{19}$. The PAPAYA study shows that the majority of patients still prefer completing a postal questionnaire and suggests that e-mail-based follow-up may be most useful in populations that are on average younger than the PCI patients of the present study. Currently, an individualised approach to follow-up may be a highly efficient option. Clinicians and researchers alike should try to amend their followup methods on their patients' social background, educational level and logistics such as accessibility to the internet. The observed age dependence of preference for e-mail-based follow-up suggests that this attitude may be linked to socialisation in a computer-friendly environment. As an early familiarity with computers and the internet is increasingly prevalent, a significant increase in patients who prefer e-mail-based follow-up may be expected in the future.

\section{Limitations}

There are some limitations that may have influenced the results of this survey. First, we used a postal survey, which might have resulted in lower return rates for patients who actually preferred e-mail or telephone follow-up. This poses as a limitation, which might have resulted in an underrepresentation of patients preferring e-mail or telephone contact. Second, one may feel that performing this study in clinical trial participants is a limitation, mostly because many randomised studies examine selected patient populations. However, this was not the case in TWENTE and DUTCH PEERS ${ }^{10,11,20,21}$. 
The breadth of these study populations and the high enrolment rates at our centre suggest that the findings are valid for PCI patients in general. Moreover, the TWENTE and DUTCH PEERS trials used both postal questionnaire and telephone-based follow-up, which means that many trial participants had experience with both approaches. A negative experience with either could have resulted in an overrepresentation of patients who preferred e-mail follow-up. Nevertheless, in the light of the experience with different methods of follow-up, it may be assumed that the participants of the PAPAYA study made carefully considered choices that should be taken seriously.

\section{Conclusions}

Patients showed a distinct preference for completing a postal questionnaire rather than being approached by telephone or e-mail. Younger patients accepted e-mail-based follow-up more often, but the majority of the youngest patients still preferred approaches other than by e-mail.

\section{Impact on daily practice}

Knowledge of the patient-preferred mode for follow-up assessment is crucial in order to keep patients in long-term clinical follow-up programmes after PCI. The PAPAYA study shows that the majority of patients still prefer completing a postal questionnaire and suggests that e-mail-based follow-up may be most useful in populations that are on average younger than the population of the present study. The age dependence of the preference for e-mail suggests that this preference will increase in the future. Currently, an individualised approach may be a highly efficient option.

\section{Acknowledgements}

We thank Mrs. Renate E. van der Leest (Thoraxcentrum Twente, Enschede, The Netherlands) for her conscientious administrative work.

\section{Funding}

This investigator-initiated study was performed by the Cardiology Department of Thoraxcentrum Twente and by CardioResearch Enschede, in cooperation with the Department of Health Technology and Services Research (HTSR) of the University of Twente, Enschede, The Netherlands. The study was performed without any extramural funding.

\section{Conflict of interest statement}

C. von Birgelen has been consultant to and has received lecture fees or travel expenses from Abbott Vascular, Boston Scientific, and Medtronic; he received lecture fees from MSD and AstraZeneca. The institution has received research grants, provided by Abbott Vascular, Biotronik, Boston Scientific, and Medtronic. M. IJzerman is consultant to PANAXEA b.v.; he has received payments for lectures from Roche, Pfizer, and Sanofi Aventis. The other authors have no conflicts of interest to declare.

\section{References}

1. Daemen J, Wenaweser P, Tsuchida K, Abrecht L, Vaina S, Morger C, Kukreja N, Jüni P, Sianos G, Hellige G, van Domburg RT, Hess OM, Boersma E, Meier B, Windecker S, Serruys PW. Early and late coronary stent thrombosis of sirolimus-eluting and paclitaxel-eluting stents in routine clinical practice: data from a large two-institutional cohort study. Lancet. 2007;369:667-78.

2. Räber L, Magro $M$, Stefanini GG, Kalesan B, van Domburg RT, Onuma Y, Wenaweser P, Daemen J, Meier B, Jüni P, Serruys PW, Windecker S. Very late coronary stent thrombosis of a newer-generation everolimus-eluting stent compared with earlygeneration drug-eluting stents: a prospective cohort study. Circulation. 2012;125:1110-21.

3. Probstfield JL, Frye RL. Strategies for recruitment and retention of participants in clinical trials. JAMA. 2011;306:1798-9.

4. Windecker S, Serruys PW, Wandel S, Buszman P, Trznadel S, Linke A, Lenk K, Ischinger T, Klauss V, Eberli F, Corti R, Wijns W, Morice MC, di Mario C, Davies S, van Geuns RJ, Eerdmans P, van Es GA, Meier B, Jüni P. Biolimus-eluting stent with biodegradable polymer versus sirolimus-eluting stent with durable polymer for coronary revascularisation (LEADERS): a randomised non-inferiority trial. Lancet. 2008;372:1163-73.

5. Onuma Y, Miquel-Hebert K, Serruys PW; SPIRIT II Investigators. Five-year long-term clinical follow-up of the XIENCE V everolimus-eluting coronary stent system in the treatment of patients with de novo coronary artery disease: the SPIRIT II trial. EuroIntervention. 2013;8:1047-51.

6. Serruys PW, Farooq V, Kalesan B, de Vries T, Buszman P, Linke A, Ischinger T, Klauss V, Eberli F, Wijns W, Morice MC, Di Mario C, Corti R, Antoni D, Sohn HY, Eerdmans P, RademakerHavinga T, van Es GA, Meier B, Jüni P, Windecker S. Improved safety and reduction in stent thrombosis associated with biodegradable polymer-based biolimus-eluting stents versus durable polymer-based sirolimus-eluting stents in patients with coronary artery disease: final 5-year report of the LEADERS randomized, noninferiority trial. JACC Cardiovasc Interv. 2013;6:777-89.

7. Tak HJ, Ruhnke GW, Meltzer DO. Association of patient preferences for participation in decision making with length of stay and costs among hospitalized patients. JAMA Intern Med. 2013;173:1195-205.

8. The World Bank. Available at: http://data.worldbank.org/ indicator/IT.NET.USER.P2 (accessed June 15, 2015).

9. Central Bureau of Statistics (CBS). Available at: http://www. cbs.nl/nl-NL/menu/themas/vrije-tijd-cultuur/publicaties/artikelen/ archief/2013/2013-4005-wm.htm (accessed June 27, 2015).

10. von Birgelen $\mathrm{C}$, Basalus MW, Tandjung $\mathrm{K}$, van Houwelingen KG, Stoel MG, Louwerenburg JH, Linssen GC, Saïd SA, Kleijne MA, Sen H, Löwik MM, van der Palen J, Verhorst PM, de Man FH. A randomized controlled trial in second-generation zotarolimus-eluting Resolute stents versus everolimus-eluting Xience V stents in real-world patients: the TWENTE trial. J Am Coll Cardiol. 2012;59:1350-61. 
11. von Birgelen C, Sen H, Lam MK, Danse PW, Jessurun GA, Hautvast RW, van Houwelingen GK, Schramm AR, Gin RM, Louwerenburg JW, de Man FH, Stoel MG, Löwik MM, Linssen GC, Saïd SA, Nienhuis MB, Verhorst PM, Basalus MW, Doggen CJ, Tandjung K. Third-generation zotarolimus-eluting and everolimuseluting stents in all-comer patients requiring a percutaneous coronary intervention (DUTCH PEERS): a randomised, single-blind, multicentre, non-inferiority trial. Lancet. 2014;383:413-23.

12. Edwards PJ, Roberts I, Clarke J, Diguiseppi C, Wentz R, Kwan I, Cooper R, Felix LM, Pratap S. Methods to increase response to postal and electronic questionnaires. Cochrane Database Syst Rev. 2009;8:MR000008.

13. Pfisterer M; Trial of Invasive versus Medical therapy in Elderly patients Investigators. Long-term outcome in elderly patients with chronic angina managed invasively versus by optimized medical therapy: four-year follow-up of the randomized Trial of Invasive versus Medical therapy in Elderly patients (TIME). Circulation. 2004;110:1213-8.

14. Galloe AM, Thuesen L, Kelbaek H, Thayssen P, Rasmussen K, Hansen PR, Bligaard N, Saunamäki K, Junker A, Aarøe J, Abildgaard U, Ravkilde J, Engstrøm T, Jensen JS, Andersen HR, Bøtker HE, Galatius S, Kristensen SD, Madsen JK, Krusell LR, Abildstrøm SZ, Stephansen GB, Lassen JF; SORT OUT II Investigators. Comparison of paclitaxel- and sirolimus-eluting stents in everyday clinical practice: the SORT OUT II randomized trial. JAMA. 2008;299:409-16.

15. Maeng M, Tilsted HH, Jensen LO, Krusell LR, Kaltoft A, Kelbæk H, Villadsen AB, Ravkilde J, Hansen KN, Christiansen EH, Aarøe J, Jensen JS, Kristensen SD, Bøtker HE, Thuesen L, Madsen M, Thayssen P, Sørensen HT, Lassen JF. Differential clinical outcomes after 1 year versus 5 years in a randomised comparison of zotarolimus-eluting and sirolimus-eluting coronary stents (the SORT OUT III study): a multicentre, open-label, randomised superiority trial. Lancet. 2014;383:2047-56.

16. Antonsen L, Thayssen P, Hansen H, Maeng M, Tilsted HH, Bøtker HE, Ravkilde J, Madsen M, Sørensen HT, Thuesen L, Lassen JF, Jensen LO. Outcomes after revascularisation with everolimus- and sirolimus-eluting stents in patients with acute coronary syndromes and stable angina pectoris: a substudy of the SORT OUT IV trial. EuroIntervention. 2014;10:212-23.

17. Thuesen L, Jensen LO, Tilsted HH, Mæng M, Terkelsen C, Thayssen P, Ravkilde J, Christiansen EH, Bøtker HE, Madsen M, Lassen JF. Event detection using population-based health care databases in randomized clinical trials: a novel research tool in interventional cardiology. Clin Epidemiol. 2013;5:357-61.

18. Stefanini GG, Windecker S. Stent performance: never too late to sort it out. Lancet. 2014;383:2024-6.

19. Chawla NV, Davis DA. Bringing big data to personalized healthcare: a patient-centered framework. J Gen Intern Med. 2013;28:S660-5.

20. Sen H, Tandjung K, Basalus MW, Löwik MM, van Houwelingen GK, Stoel MG, Louwerenburg HW, de Man FH, Linssen GC, Nijhuis R, Nienhuis MB, Verhorst PM, van der Palen J, von Birgelen C. Comparison of eligible non-enrolled patients and the randomised TWENTE trial population treated with Resolute and Xience V drug-eluting stents. EuroIntervention. 2012;8: 664-71.

21. Tandjung K, Sen H, Lam MK, Basalus MW, Louwerenburg JH, Stoel MG, van Houwelingen KG, de Man FH, Linssen GC, Saïd SA, Nienhuis MB, Löwik MM, Verhorst PM, van der Palen J, von Birgelen C. Clinical outcome following stringent discontinuation of dual antiplatelet therapy after 12 months in real-world patients treated with second-generation zotarolimus-eluting resolute and everolimus-eluting Xience V stents. 2-year follow-up of the randomized TWENTE trial. J Am Coll Cardiol. 2013;61: 2406-16.

\section{Supplementary data}

Online Table 1. Preferred mode and frequency of follow-up assessment questionnaire.

Online Table 2. Preference regarding follow-up assessment in all responders, and in gender and age-based groups.

The supplementary data are published online at:

http://www.pcronline.com/

eurointervention/97th_issue/288 


\section{Supplementary data}

Online Table 1. Preferred mode and frequency of follow-up assessment questionnaire.

1. Please state which type of approach do you feel is acceptable for collecting follow-up information after your treatment? (Multiple answers allowed)

$\square$ Postal questionnaires

$\square$ Telephone contact

$\square$ E-mail contact

2. Please indicate which type of approach you prefer the most. (Please state only 1 answer)

$\square$ Postal questionnaires

$\square$ Telephone contact

$\square$ E-mail contact

$\square$ No preference

3. Please indicate which type of approach you prefer the least. (A maximum of 2 options is allowed)

$\square$ Postal questionnaires

$\square$ Telephone contact

$\square$ E-mail contact

4. In case you would prefer telephone contact for collecting follow-up information after your treatment, which time of day do you prefer to be contacted?

\section{$\square$ Morning}

$\square$ Afternoon

\section{$\square$ Evening}

5. Please indicate how many follow-up assessments per year you would prefer, after your treatment? (Please state only 1 answer)

\begin{tabular}{|c|c|}
\hline & $\square 0$ times per year* \\
\hline & $\square 1$ time per year \\
\hline & $\square 2$ times per year \\
\hline & $\square 3$ times per year \\
\hline & $\square 4$ times per year \\
\hline & $\begin{array}{l}\text { * I would prefer not to be approached for follow-up information, } \\
\text { but I would allow my doctor/clinical researcher to use the } \\
\text { information available in my medical files, from my general- } \\
\text { practitioner or pharmacy. }\end{array}$ \\
\hline 6. & $\begin{array}{l}\text { In case you stated postal questionnaires or e-mail as your } \\
\text { preferred mode of follow-up, how many questions do you feel } \\
\text { are acceptable? (Please state only } 1 \text { answer) }\end{array}$ \\
\hline & $\square \leq 5$ questions \\
\hline & $\square 6$-10 questions \\
\hline & $\square$ 11-15 questions \\
\hline & $\square>15$ questions \\
\hline 7. & $\begin{array}{l}\text { In case you stated telephone contact as your preferred mode of } \\
\text { follow-up, how many questions do you feel are acceptable? } \\
\text { (Please state only } 1 \text { answer) }\end{array}$ \\
\hline & $\square \leq 5$ questions \\
\hline & $\square 6$-10 questions \\
\hline & $\square 11-15$ questions \\
\hline & $\square>15$ questions \\
\hline
\end{tabular}




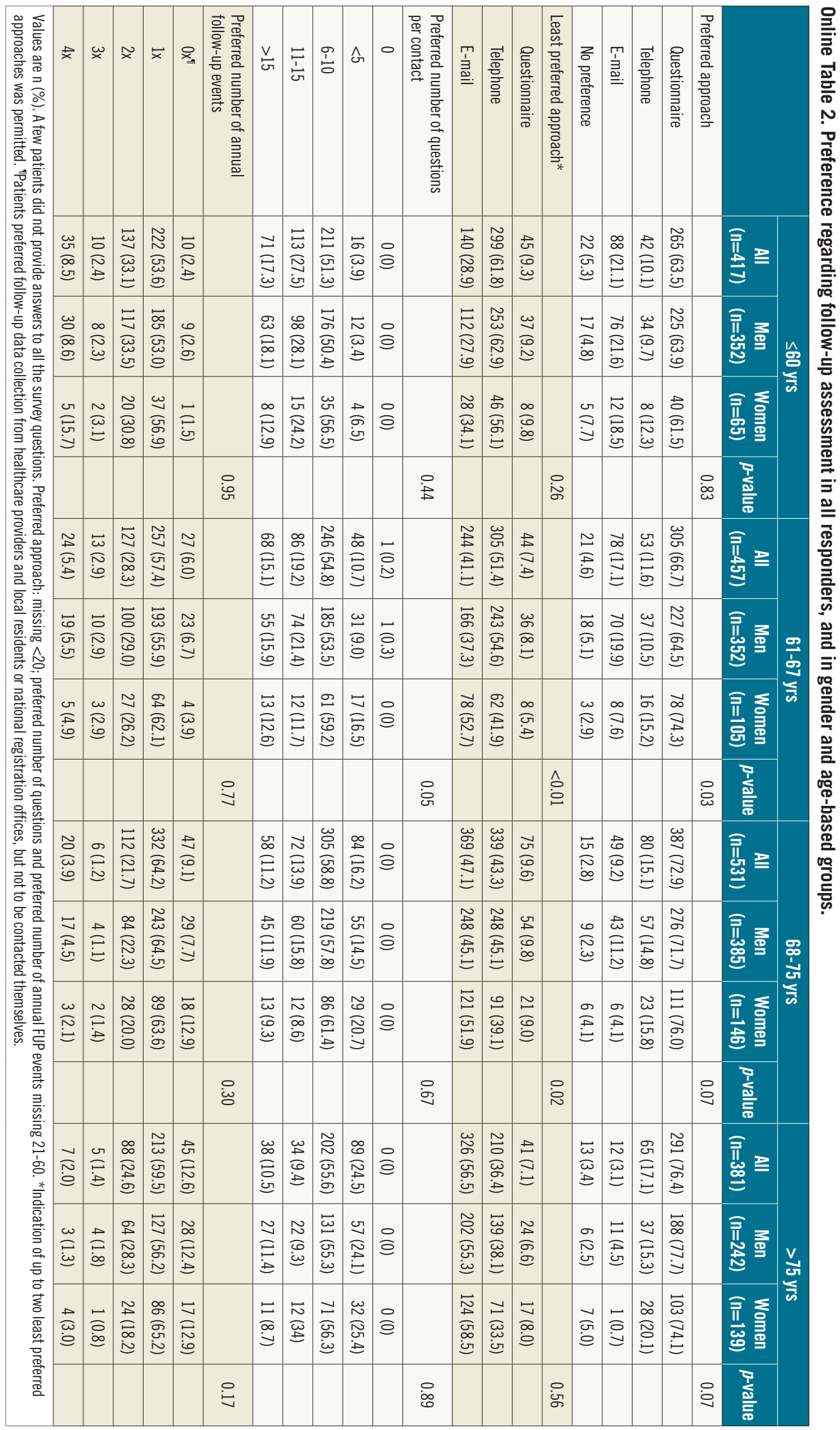

